\title{
The politics of establishing catchment management agencies in South Africa: the case of the Breede-Overberg Catchment Management Agency
}

\author{
Richard Meissner $^{1,2}$, Nikki Funke $^{1}$ and Karen Nortje ${ }^{1}$
}

\begin{abstract}
We reflect on the politics of establishing catchment management agencies in South Africa with a specific focus on the Breede-Overberg Catchment Management Agency (BOCMA), which was recently replaced by the Breede-Gouritz Catchment Management Agency (BGCMA). We do so by applying the framework of adaptive comanagement and its institutional prescriptions: collaboration, experimentation, and a bioregional approach. We start by introducing the history of this catchment management agency (CMA) and then describe the establishment of CMAs in South Africa in general and that of BOCMA in particular. We follow the framework for rule types and types of river basin organizations set out by the editors of this special feature with reference to adaptive comanagement where applicable. We then discuss the politics and strategies involved in the introduction of the CMA concept to the National Water Act and the latest developments around these institutions in South Africa. This is followed by reflections on what can be surmised about BOCMA's democratic functioning and performance to date. We conclude by reflecting on the future of operations of the new BGCMA and CMAs in South Africa in general. While our research shows that BOCMA's establishment process has featured several elements of adaptive comanagement and its institutional prescriptions, it remains to be seen to what extent it is possible to continue implementing this concept when further developing and operationalizing the BGCMA and the country's other CMAs.
\end{abstract}

Key Words: adaptive co-management; Breede-Gouritz Catchment Management Agency; Breede-Overberg Catchment Management Agency; catchment management agency; river basin organization; South Africa

\section{INTRODUCTION}

For a considerable part of South Africa's history, the management and allocation of common-pool resources were largely determined by racial politics. Under the policy of apartheid, black people in South Africa were deprived of most basic rights. This included the right to access to potable water and sanitation as a result of the Department of Water Affairs' (DWA) policy to apportion and control South Africa's water resources. For instance, the independent black homelands, which had been created by the apartheid regime as areas of separate development for a large percentage of the country's black population, had to negotiate with the national South African government to obtain water rights and had to compete with water users outside of their territories to obtain water use permits. Water can therefore be interpreted as having been used as a weapon of oppression and control of the black majority by the apartheid state (Funke et al. 2007).

Because of this state of affairs, the way in which water resources were managed and allocated required serious revision once apartheid had been abolished and the first democratic government came to power in 1994. One area in particular that needed urgent attention was that of water supply and sanitation, which was characterized by a significant backlog that the new South African government had inherited from its apartheid predecessor (Schreiner et al. 2002). To be exact, in 1994, 35\% of South Africans had no access to a basic water supply, and 53\% lived without proper sanitation (DWAF 2004a). Given this injust and unequal situation, the government has developed and attempted to implement a suite of water reforms from 1994 onwards (Schreiner et al. 2002).
A key principle underlying the South African government's water resources management transformation strategy, particularly between 1996 and 1998, has been integrated water resources management (IWRM; Jonker 2007). In the South African context, IWRM can be understood as realizing the need for integrated management of all aspects of water resources, delegating management functions, and achieving the participation of citizens in water resources management (Claassen 2013). Accordingly, the country's National Water Act (Republic of South Africa 1998, Act 36) features a focus on decentralization and an emphasis on stakeholder consultation in water resources management-related decision-making processes. The concept of decentralization is based on the subsidiarity principle as enshrined in the South African Constitution (Republic of South Africa 1996, Act 108), which stipulates that those functions that can be more efficiently and effectively carried out by lower levels of government should be delegated to the lowest appropriate level (Funke et al. 2007). The concepts of decentralization and stakeholder consultation are particularly relevant the work we present here, in which we investigate the institutional design, types, politics, and performance of catchment management agencies (CMAs), which constitute South African equivalents of river basin organizations (RBOs). Throughout the analysis, we pay particular attention to a case study, the Breede-Overberg Catchment Management Agency (BOCMA), and reflect upon its establishment and possible future developments that may take place regarding its operations and functioning, as well as those of CMAs more generally. We do so by using a theoretical framework comprising two parts. The first part of the framework deals with the institutional design of RBOs, types of RBOs, the politics and strategies involved in RBO 
formation, and issues related to the democratic functioning and performance of RBOs. More details about this part of the framework are discussed in the introduction to this special feature (Huitema and Meijerink 2016). The second part of the framework is based on adaptive management, for which we adopt the views of Lee (1993, 1999) and Huitema et al. (2009), who associate this concept with three institutional prescriptions: collaboration, experimentation, and a bioregional approach to water resources management. Collaboration, can be defined as the inclusion of various stakeholders in the process of decision making (Lee 1999) toward better quality choices and legitimacy of management. While this term is often also referred to as public participation (Huitema et al. 2009), the latter only makes up a small part of the process of trust building and the inclusion of different voices that are needed for legitimacy within the process of collaboration. It is for this reason that we use the term stakeholder engagement, which encompasses public participation processes as well as other engagement processes and methods. Experimentation is about adaptation through learning, particularly in the context of uncertainty (Lee 1999). Bioregionalism can be interpreted as the implementation of management structures at the river basin level (Huitema et al. 2009), thereby either crossing administrative or political boundaries, or not coinciding with the latter (Lee 1999).

The two components of the framework are closely linked and together form a comprehensive and effective lens for RBO analysis. Examples of complementarities between the two components include the major role that the concepts of collaboration and experimentation play in the CMA establishment process, and in particular, in terms of authority and aggregation rules. Another obvious link is that between the notion of bioregionalism and the boundary rules according to which CMAs in South Africa have been established. These and further links are highlighted throughout this article.

In terms of methodology, we made use of a mixed-methods approach to conduct the research. This took the form of a desktop study to identify and analyze literature that had been published on CMAs in general and BOCMA in particular, as well as semistructured interviews with individuals who were either involved in the establishment of BOCMA or who are currently conducting research on the CMA. A one-day field trip to the Breede River area was also undertaken to allow us to get a sense of the circumstances and natural environmental realities that characterize some parts of the water management area (WMA). Through the interviews and field trip, we were able to gather insights into the establishment of BOCMA that are not contained in current Department of Water and Sanitation (DWS) publications or previous research. In other words, using the interviews and field trip provided a novel understanding of BOCMA's establishment.

We first present a brief note on CMAs in South Africa, before introducing the Breede-Gouritz WMA, where BOCMA is situated. This is followed by a brief history of the establishment of BOCMA, before moving on to the institutional design of CMAs, with particular reference to BOCMA, in terms of the various rule types as outlined by Huitema and Meijerink (2016) in the introduction to this special feature. We subsequently discuss different types of RBOs, followed by a section on the politics and strategies involved in the introduction of the CMA concept to the National Water Act, and the latest developments around CMAs in South Africa. This is followed by reflections on what can be surmised about BOCMA's democratic functioning and performance to date in relation to the concept of adaptive comanagement, as well as final conclusions.

A brief note on catchment management agencies in South Africa In October 1999, the South African government established 19 WMAs, which can be classified as bioregions because their boundaries are along catchment divides but do not coincide with administrative boundaries as defined by local government. At the time, the establishment of 19 CMAs, one per WMA, was envisaged. The CMAs are meant to perform certain management functions with which they have been tasked and are also required to cooperate and seek agreement on water-related matters among various stakeholders and interested parties. This requirement fits in with the institutional prescription of collaboration between governmental and nongovernmental stakeholders that forms part of adaptive comanagement (Huitema et al. 2009). Currently, these management functions are still the responsibility of the DWS, which, it is important to note, was known as the Department of Water Affairs and Forestry (DWAF) between 1994 and 2009, and as the Department of Water Affairs (DWA) between 2009 and May 2014.

A CMA is governed by a governing board to ensure stakeholder representativeness and to prevent powerful parties with vested interests from exercising control over other parties. According to Armitage et al. (2009), such power asymmetries are an important element of adaptive comanagement that needs to be monitored and addressed to determine when and how it emerges and persists. In addition, CMAs have a mandate to develop catchment management strategies (CMS), which constitute a plan to realize the protection, use, development, conservation, management, and control of water resources in their respective WMAs (DWAF 2004d, Funke et al. 2007; D. Weston, Pegasys Consulting, personal communication, 12 September 2012).

In 2012, DWA made a decision to reduce the number of planned CMAs from 19 to 9 because, at the time, only 2 CMAs had been established (DWA 2013). Furthermore, this reduction in the number of CMAs is the result of a reconsideration of the management model and viability assessments related to water resources management, funding, capacity, skills, and expertise in regulation and oversight, and an effort to improve integrated water systems management. The nine CMAs are: Limpopo, Olifants (Mpumalanga Province), Inkomati-Usuthu, PongolaUmzimkulu, Vaal, Orange, Mzimvubu-Tsitsikamma, BreedeGouritz, and Berg-Olifants (Western Cape Province; DWA 2013).

This development links to the experimentation prescription of adaptive management, according to which management itself can be interpreted as a form of experimentation (Huitema et al. 2009). Another important element of adaptive comanagement that is relevant here is the idea of assessment, which can enable one to identify appropriate institutional responses to change, to facilitate an adaptive approach, and to secure learning at multiple levels (Armitage et al. 2009). Similarly, Walker et al. (in preparation as cited in Olsson et al. 2004) use the concept of transformability to describe the move of a social-ecological system to a new way of operating in a situation where existing ecological, economic, and social structures become unsustainable. In terms of experimentation, assessment, and transformability, DWS was therefore forced to adapt its approach to CMA establishment to 
Fig. 1. Map of the Breede Water Management Area. Source: DWAF (2004b).

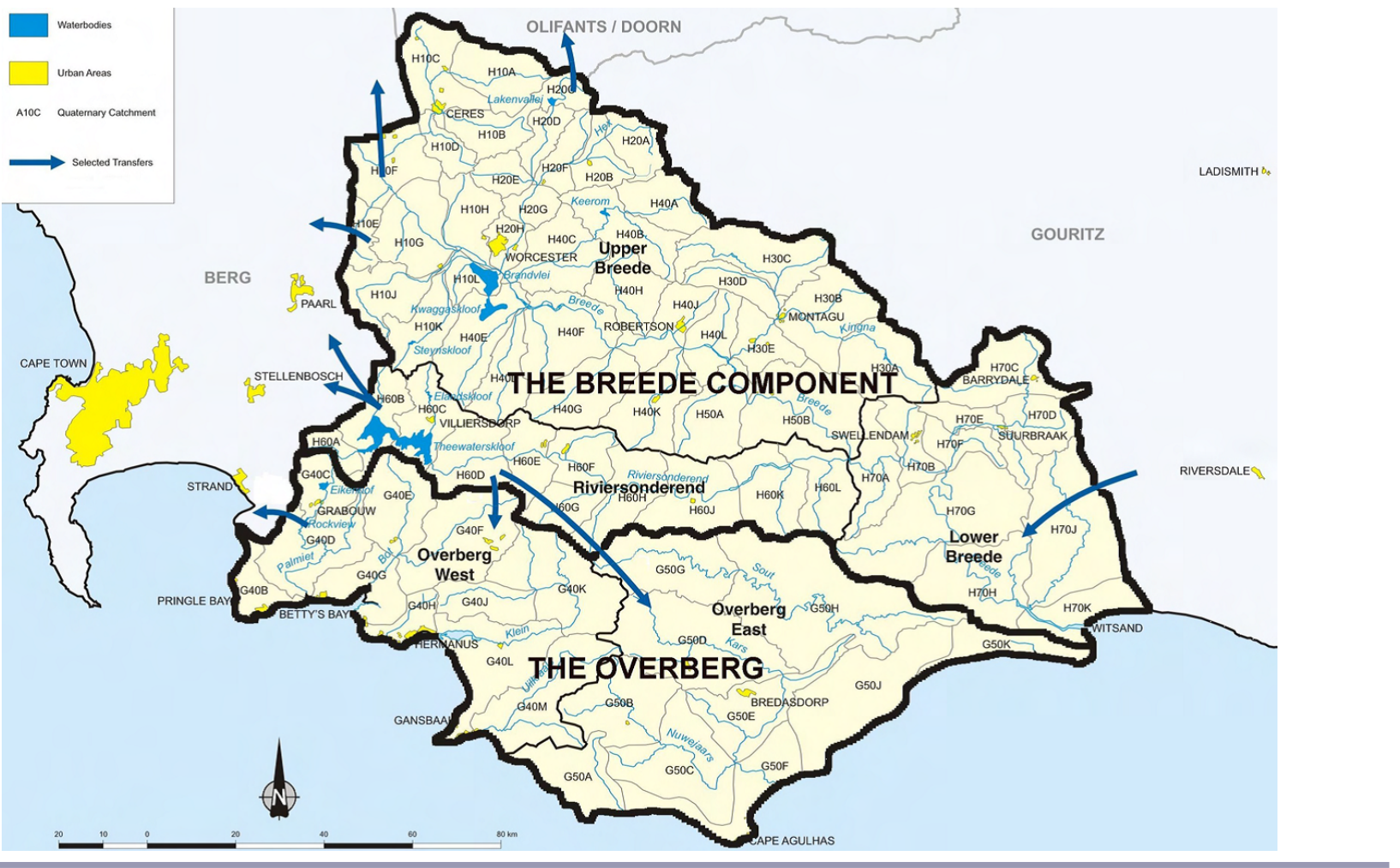

address the numerous challenges that had marked more than a decade of "failed" CMA experimentation.

We are aware that since the finalization of our research, BOCMA has been replaced by the Breede-Gouritz CMA (BGCMA). The latter organization was established in May 2014 because of DWS's decision to extend BOCMA's water management area boundary (Republic of South Africa 2014). The BGCMA is, however, not yet up and running because human resources issues first need to be addressed (S. Stuart-Hill, University of Kwa-Zulu Natal, personal communication, 24 July 2015). We therefore only deal with the establishment process of BOCMA and not BGCMA.

\section{Overview of the Breede-Gouritz Water Management Area}

With the amalgamation of the Breede WMA and the Gouritz WMA, the former BOCMA's geographical area (Fig. 1) has increased substantially. As a result, the BGCMA is now bordered by the Indian Ocean to the south, the Berg-Olifants WMA to the west, the Orange River WMA to the north, and the MzimvubuTsitsikama WMA to the east (Fig. 2). The largest portion of the WMA falls within the Western Cape Province, with only small portions extending into the Eastern Cape and Northern Cape provinces. The two largest rivers in the WMA are the Breede and Gouritz rivers. The Breede River's main tributary is the Riversonderend River. The largest tributaries of the Gouritz River are the Gamka, Groot, and Olifants rivers. Both the Breede and Gouritz rivers discharge into the Indian Ocean (DWA 2012).

The major economic sectors in the BGCMA are agriculture, agricultural processing, and coastal tourism, which make the economic base of the area quite dependent on the availability and health of water resources. The allocation of water to agriculture and coastal tourism has a direct bearing on the economic growth pathways of these sectors and on the natural ecosystems that support tourism. In addition, petroleum production (including petroleum byproducts) and interbasin transfers contribute to the BGCMA's dependence on water resources. There are currently indications that the Breede-Overberg parts of the BGCMA's water resources are stressed and that aquatic ecosystem health is deteriorating. In addition, the Gouritz part of the BGCMA is experiencing a water deficit, which means that effective water conservation and water demand management as well as reconciliation actions are of critical importance (BOCMA 2011, DWA 2012).

Fig. 2. Map showing the Breede-Gouritz Water Management Area (WMA) after amalgamation of the Breede and Gouritz WMAs. Source: DWAF (2004c).

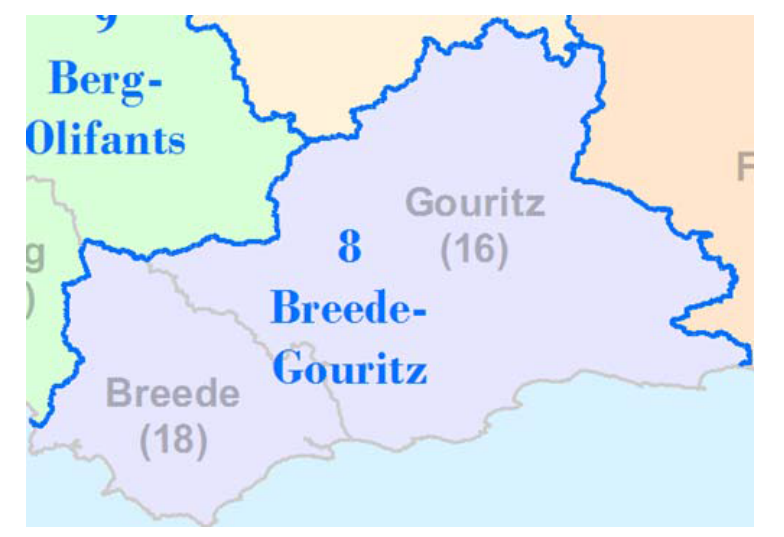


Establishment of the Breede-Overberg Catchment Management Agency

BOCMA was established in 2005 under the National Water Act (BOCMA 2011), and the BOCMA Governing Board was established two years later (D. Weston, personal communication). Prior to the establishment of the CMA and the development of its CMS, the Western Cape Regional Office of DWAF was fully responsible for the management of the catchment's water resources through the WMA's internal strategic perspective (DWAF 2004d). According to McConkey et al. (2005), the establishment of BOCMA was the result of deliberate negotiations between various stakeholders, assisted by the Western Cape Regional Office of DWAF. The main conduit for this stakeholder process was the BOCMA Reference Group, which consisted of representatives from various sectors (D. Weston, personal communication).

Several actors were involved in the CMA's establishment process, in particular DWAF at the national and regional level, and stakeholders that formed part of the BOCMA Reference Group. In addition, a well-known consultancy in the South African water sector played a key role in facilitating stakeholder engagement throughout the BOCMA establishment process (D. Weston, personal communication). The first step in the development of the CMS was the identification of stakeholders and previously disadvantaged groups, for example, emerging farmers (BOCMA 2009). Emerging farmers may be defined as those black farmers who receive support to engage in agriculture and who have a desire to increase commercialization of their production (Denison and Manona 2007, van Averbeke 2008). In May 2010, a networking meeting was held with all governmental authorities: provincial and semigovernment departments, local and district municipalities, and water user associations. The meeting's objective was to ascertain how the planning priorities would influence BOCMA's planning processes (BOCMA 2010).

In terms of adaptive comanagement, it is therefore evident that considerable stakeholder engagement efforts, including public participation events, characterized the BOCMA establishment process to ensure the inclusion of a wide range of stakeholder voices in the CMA's establishment. While this is commendable, in-depth research into the actual modes and results of this participation is needed to determine whether these efforts have been successful to date and what effects they are likely to have on the future running of the expanded BGCMA. It is relevant to refer to Huitema et al. (2009), who warn that public participation processes have been criticized because it is difficult to assess their level of success. Moreover, in many cases, stakeholders complain that although they were consulted, they cannot be guaranteed that they have actually influenced that particular process or decision (Huitema et al. 2009). In addition, in South Africa, stakeholder engagement processes such as public participation have not been as succesfull as initially envisaged in the National Water Act. In fact, Du Toit and Pollard (2008) argue, "South Africa has yet to implement a comprehensive and functional approach to stakeholder engagement at the level of water management areas." As a result, South African stakeholders often become confused, bored, demotivated, and fatigued (Du Toit and Pollard 2008).

\section{INSTITUTIONAL DESIGN}

The editors and authors of this special feature (Huitema and Meijerink 2016) examine five types of rules in their analysis of different institutional arrangements; based on these rule types, they also discuss different RBO types. In this section, we deal with institutional design by first classifying CMAs and BOCMA in terms of these different rule types. We then proceed to discuss the CMAs and BOCMA according to different RBO types.

\section{Rule types}

The rule types referred to in this special feature (Huitema and Meijerink 2016) are authority rules, aggregation rules, boundary rules, information rules, and pay-off rules. In the case of CMAs in general and BOCMA in particular, we summarize the rules that have become evident in CMA establishment and functioning (Table 1).

\section{Authority rules}

CMAs are statutory bodies established under the terms of the National Water Act and are able to develop their own CMS. Democratic control is also exercised through the governing board, which is representative of all stakeholders and their interests in the WMA for which the CMA is responsible. It is in this regard that BOCMA has, to date, played a coordination governance function by coordinating the actions of relevant stakeholders, including various actions along the governance value chain such as financially sustaining the CMA, distributing benefits, and resolving disputes. This coordination takes place on a horizontal, cross-sectoral level. Regarding the influence that other actors have on the functioning of CMAs, reference can be made to the Minister of Water and Sanitation's key role in CMA establishment. The minister appoints the governing board and can remove board members for good reason, whereas the CMA oversees its institutional functioning (DWAF no date). In this respect, the minister plays several functions: rule-making, construction of collective entities, coordination, monitoring, enforcement, and initial financing.

Although stakeholder engagement is firmly enshrined in the National Water Act and the Breede-Overberg CMS, which is in line with the concept of adaptive comanagement, BOCMA has nonetheless been governed by a stringent hierarchy. The highest ranking decision maker is the Minister of Water and Sanitation, who makes the most challenging and important decisions such as appointing the CMA board or approving the CMS. After the minister, the board of directors is tasked with making important decisions, which must adhere to the stipulations contained in the National Water Act (e.g., equity considerations, stakeholder participation, and others) and the decisions of the Ministry of Water and Sanitation.

Here, it is necessary to reflect on a particularly important point as far as the autonomous functioning of CMAs in South Africa is concerned. As noted, the power to appoint the CMA's board rests with the Minister of Water and Sanitation. While one could argue that this extent of power in the Minister's hands negates the CMA's autonomous functioning, a counter-argument can be made for the importance of ensuring a reasonable degree of representivity at the CMA board level. This is especially important given the diversity of stakeholders in many WMAs, and the differing degrees of education, capacity, agency, power, and so on between, for example, marginalized water users and 
Table 1. Rule types evident during the establishment and functioning of catchment management agencies.

\begin{tabular}{|c|c|}
\hline Rule type & Rules in case study \\
\hline Authority rules & $\begin{array}{l}\text { - Catchment management agencies (CMAs) are quite autonomous and have some internal mechanisms for democratic } \\
\text { control, and the Minister of Water and Sanitation has a strong influence on the appointment of the governing board } \\
\text { - The strategy and functioning of a CMA is contained in its catchment management strategy, which must do the following: } \\
\text { set principles for water allocation; take into account all matters related to water resource protection, use, development, } \\
\text { conservation, management, and control; be in harmony with the National Water Resources Strategy; and be reviewed every } \\
\text { five years }\end{array}$ \\
\hline Aggregation rules & $\begin{array}{l}\text { - In the run-up to the development of CMAs, individual views need to be accommodated by means of public participation } \\
\text { processes } \\
\text { - In the case of the Breede-Overberg Catchment Management Agency (BOCMA), two separate stakeholder engagement } \\
\text { processes took place: one in the Overberg area and the other in the Breede River basin. In the Overberg area, public } \\
\text { participation took the form of a series of public meetings; in the Breede River basin, public participation was closely linked } \\
\text { to the Breede River basin study } \\
\text { - Decision-making at the governing board level takes place through democratic agreement (consensus), cooperation, and } \\
\text { open discussions in meetings }\end{array}$ \\
\hline
\end{tabular}

Boundary rules

- CMAs have a strong focus on stakeholder engagement, and rules are inclusive because provision is made for stakeholders to participate in catchment forums, catchment steering committees, and as part of the governing board. A wide variety of actors are involved in the CMA organizational structures to represent as many sectors as possible. These sectors can include environmental interest groups, local and provincial government, business and industry, poor and rural settlements, the agricultural sector, and nongovernmental organizations. However, being represented on an organizational structure is not the same as having power and influence in that structure. In the South African context, it is typically those with the most resources and political clout who have the most influence in such structures

- BOCMA's area of responsibility has been the Breede-Overberg Water Management Area (WMA), whereas the BreedeGouritz Catchment Management Agency (BGCMA) will be responsible for the amalgamated Breede-Gouritz WMA. Two considerations were deemed important at the time of establishing the country's original 19 WMAs: the natural hydrological boundaries and the potential for achieving the CMA's financial viability in the medium to long term

Information rules

- The scientific community played an important role in the development of BOCMA's catchment management strategy as well as the early development of the CMA through the Breede River basin study and has therefore influenced the language of the CMA. In addition, this community has been very active and influential in studying the challenges facing the CMA process and making recommendations about what could be done to address those challenges in future. However, relying too much on technocratic knowledge and its often simplistic understanding of a complex world at the expense of other kinds of knowledge could prove to be problematic

Pay-off rules
- A CMA can be funded or recover costs from water use charges levied in its WMA (in terms of the pricing strategy for water use charges set by the Minister of Water and Sanitation), from money from any other lawful sources (e.g., grants, loans), or from money appropriated by Parliament
- Some of BOCMA's funding has come from water management charges levied on water users. The agency also received seed funding from the Department of Water and Sanitation. It now remains to be seen how benefits and costs will be distributed in the new BGCMA. Currently, it seems that powerful actors stand to benefit more than marginalized actors

established commercial farmers (A. Anderson, Crossflow Consulting, personal communication, 11 September 2012). BOCMA's governing board has had representation from many corners and includes the following groups: the Western Cape Provincial Government, civil society, industry and business, commercial agriculture, conservation, poor and rural settlements, and emerging farmers (BOCMA: http://www.bocma.co.za).

Brown (2011) substantiates the need for strong government intervention when appointing a CMA board and argues that given the particularities of the South African context, it may make sense to reassess and, potentially, strengthen the role of the state in participatory water resources management. In addition, Brown (2011:180) challenges the widely held assumption that "the higher the level of power devolved to participatory institutions at the local level... the greater the outcomes in terms of efficiency and social equity." The danger exists that strong stakeholder participation may reinforce rather than reduce inequalities in the case of asymmetrical power structures. To tie in with this point, a laissez-faire approach by DWAF could have resulted in a lack of representivity on the board of the two existing CMAs, with the power in the hands of the empowered stakeholder groups at the expense of their marginalized counterparts. According to Huitema et al. (2009), polycentric governance systems are well suited to adaptive comanagement because they are generally able to cope well with change and uncertainty. However, as shown in the case of BOCMA, CMAs in South Africa may require a governance system that pursues polycentrism but that is structured and hierarchical at the same time.

In addition to, and perhaps over and above, representivity, it is increasingly recognized that it is vital for a board to have the skills and capacity to function effectively. These considerations are likely to become increasingly prominent in the CMA board establishment process (D. Weston, personal communication). BOCMA's governing board has featured a range of competencies, 
including a water resource manager, water resource planner, catchment management coordinator, water allocation reform officer, water use manager, water use specialist, water use officer, licensing clerk, participation and stakeholder engagement manager, water liaison officer, data manager, water data officer, and data capturer. While the board has appointed people to fill these positions and has reportedly been doing well to date in terms of operational decision making (D. Weston, personal communication), it remains to be seen how well and to what effect these positions will be used, especially when challenges present themselves (BOCMA: http://www.bocma.co.za) in the context of the new BGCMA.

Aggregation rules

In terms of aggregation rules, individual views are accommodated in the stakeholder engagement phase when catchment forums are formed in the run-up to developing a proposal to establish a CMA. The main purposes of this phase are to ensure that trusting and constructive relationships are developed among all stakeholders and interest groups and to find a common vision. While the CMA proposal is being developed, stakeholders may feel that a formal committee, representative of all stakeholders, may be required to guide the CMA establishment process. This would take the form of a catchment steering committee. Once the CMA is established, the Minister, responding to the advice of an advisory committee, appoints the governing board, which must represent all stakeholders (including current and potential user groups) and the interests they have in the WMA (DWAF no date).

While this process is commendable and forms an important part of adaptive comanagement, it can also be extremely complicated and time consuming to include the views and inputs of hundreds of stakeholders in the CMA development process. Furthermore, stakeholders may not have the time or be interested enough to participate in this process in the first place. It is probably also extremely challenging to streamline these hundreds of views into a single voice by means of finding a representative set of stakeholders to serve on a stakeholder committee. This is likely to have been one of the reasons why the CMA establishment process in South Africa has been so slow, and why DWS has had to rethink the establishment of CMAs altogether.

In terms of BOCMA's establishment process, two separate stakeholder engagement processes took place: one in the Overberg area and one in the Breede River basin. These differed slightly from the process foreseen by the government but still fulfilled the purposes of stakeholder consultation and public participation. In the Overberg area, information sharing on CMAs and the process of developing a CMA proposal for the WMA formally commenced in 1999. A series of public meetings was held in 1999 and 2000 to inform the public about the CMA establishment process and to identify individuals, stakeholders, and interested and affected parties willing to serve on six catchment steering committees (one for each geographic region in the Overberg area). In June 2000, membership of the Overberg Stakeholder Committee was finalized; the committee was disbanded, however, after the CMA proposal was first submitted in April 2002 (DWAF 2004d).

Stakeholder engagement in the Breede River basin was closely tied to the Breede River Basin Study that started in 1999 and was published in October 2003 (DWAF 2004c). A formal engagement process ran for the duration of the study, the purpose of which was for the project team to get as much input from stakeholders as possible and to be able to share their findings with the public. The study and the CMA development process were closely linked because the stakeholder committee of the Breede River Basin Study, which was formed in 2000, was a key representative of the BOCMA Reference Group together with the Overberg Stakeholder Committee (DWAF 2004d).

The Breede River Basin Study and the Overberg Stakeholder Committees jointly decided in November 2000 that a smaller committee, the BOCMA Reference Group, would take the CMA proposal development process forward by means of working closely with DWAF and the support team (DWAF 2004d). After BOCMA's proposal had been submitted to DWAF, a waiting period ensued. During this time, the BOCMA Reference Group interacted with the advisory committee regarding the composition of the governing board that was still to be appointed. Meanwhile, capacity building of water resource committees and forums continued (McConkey et al. 2005).

To date, decision making within BOCMA has taken place by means of democratic agreement, cooperation, and open discussions in meetings (Page 2012). Generally, the CMA board has tried to reach consensus on the decisions it takes (D. Weston, personal communication). This strategy has prevented a situation in which strong board representatives are able to overwhelm weaker ones. Egalitarianism is the rationale behind this practice.

\section{Boundary rules}

In terms of boundary rules, CMAs are designed to be inclusive by providing stakeholders the opportunity to participate in catchment forums and steering committees and to be represented on the governing board (DWAF no date). During the CMA proposal drafting process, all CMAs are required to have a reference group to inform the proposal. This reference group would typically consist of 150-200 stakeholders, with the aim of representing as many sectors as possible, from conservation and environmental organizations to ratepayers' associations and forestry and service providers in the WMA. This large group is then split into smaller groups, each of which has an opportunity to give input into the CMA proposal. For BOCMA, this process was quite well run and representative (D. Weston, personal communication). The reference group included representatives from provincial government, local government, the agricultural sector, nongovernmental organizations, and environmental interest groups. The CMA proposal process was split into different phases, and the reference group was consulted for each phase. This intensive stakeholder consultation process was very inclusive but also took a very long time: nine years in total (DWAF 2004b; D. Weston, personal communication).

Another point regarding inclusivity is that in the South African context, this is not primarily about being included in a particular committee or board, but much more about the agency of different stakeholders to influence decision making and institutional processes such as CMA establishment. So, for instance, an established commercial farmer will likely have considerably more power, in the form of resources, experience, and clout, to influence decision making and institutional processes than will an emerging farmer, who may have very limited resources and experience at their disposal. That is, an emerging farmer can be represented or 
included in an organizational structure but will not necessarily have the same power or agency as a commercial farmer.

In addition, the geographical delineation of the former Breede and Gouritz WMAs as well as the combined Breede-Gouritz WMA goes back to the development of the National Water Act in the latter half of the 1990s. According to Page (2012), the following factors were important in determining the boundaries of a WMA: watercourse catchment boundaries, social and economic development patterns, efficiency considerations, and communal interests within the area in question. Two particularly important considerations were the natural hydrological boundaries and the potential for achieving the CMA's financial viability in the medium to long term (Page 2012). With regard to the establishment of the WMAs and the CMAs, it is possible that the government at the time was trying to adopt prominent concepts, noticeably IWRM and sustainability, without taking into consideration the potential difficulties related to their successful implementation. On a more positive note, DWS seems to have adopted a more flexible and adaptive interpretation of bioregionalism by consolidating the original WMAs into fewer and perceivably more financially and functionally viable ones.

\section{Information rules}

In terms of information rules, a key document containing important knowledge about the strategy and functioning of a CMA is the CMS that is required to be developed progressively and implemented. A CMS must "set principles for allocating water to existing and prospective users, take into account all matters in terms of the protection, use, development, conservation, management and control of water resources, be in harmony with the National Water Resources Strategy and be reviewed every five years" (DWAF no date:18). In terms of gathering inputs into this strategy, this has to happen in consultation with stakeholders in the WMA and go through a public consultation process (DWAF no date). It therefore appears that the experiential knowledge of stakeholders is valued highly in the official language and functioning of CMAs. CMAs, once established, are also expected to communicate relevant information to other actors in the catchment.

An actor that stands out as having had a particularly strong influence on BOCMA's CMS is the scientific community, particularly individuals from engineering, hydrology, and soil sciences that are former employees of DWS and are now independent consultants. This influence is evident in the fact that this community was involved in the design of CMAs at the national government level in the late 1990s and has since then also produced a substantial volume of research reports on how CMAs should function and be managed in terms of the National Water $A c t$, equitability (pro-poor governance approaches), IWRM, and sustainability (see Meissner et al. 2013). The scientific community has also identified a host of challenges that CMAs are likely to face in their establishment and functioning. These challenges include human, technical, and financial capacity requirements (Pegram et al. 2006). In this regard, the CMA process, including that of BOCMA, is still quite technocratic, with knowledge from the environmental sciences and engineering being highly valued (Meissner et al. 2013).

Too strong a focus on technocratic knowledge may be problematic for promoting successful adaptation in the BGCMA in future.
Plummer and Armitage (2007) argue that reductionism and science tend to render the world knowable and predictable, yet at the same time, complexity theory suggests that the world is continuously changing and adapting in response to environmental feedbacks. Therefore, technocratic knowledge produced from the environmental sciences and engineering may need to be supplemented by other kinds of knowledge to deal successfully with the challenges facing the Breede-Gouritz WMA.

Pay-off rules

In terms of pay-off rules, CMAs have certain inherent powers, that is "the powers of a natural person of full capacity," and can therefore open a bank account, enter into contracts, and borrow money. A CMA can be funded or recover costs from water use charges made in its WMA in terms of the pricing strategy for water use charges set by the Minister of Water and Sanitation, from any other lawful sources (for example, grants and loans), or from money appropriated by Parliament (DWAF no date, Republic of South Africa 2014).

In terms of BOCMA, it appears that some of the CMA's funding has come from water resources management charges levied on water users, and that this is supplemented by funding from DWS as initial "seed" funding. There has also been some international funding provided by the Dutch Unie van Waterschappen (Page 2012). This funding has, however, been limited, and there will be a need for the BGCMA to become financially independent to implement the CMS that it will be developing.

\section{River basin organization types}

Having discussed the institutional design of CMAs, we now move on to discussing their fit regarding the typology of RBOs. CMAs fall somewhere between the different types of RBOs introduced in this special feature (Huitema and Meijerink 2016). Given the authority rules that characterize them, CMAs are in some respects quite autonomous. However, they also show characteristics of agencies in that they can only be created through the Minister's approval to perform water resource management at the regional or catchment level, and in that the Minister controls the appointment of the board. This arrangement could potentially affect the independence of CMA board members. In addition, the initial functions of a CMA mostly center on coordinating the activities of water users, promoting community participation, advising DWS, and coordinating the implementation of the CMS with the water services development plans of water services authorities. The additional powers and duties around water resources management that the CMA may obtain from DWS are likely to be delegated (carried out on behalf of the Minister) at first, and only assigned (full transfer of duty to the CMA) once the CMA has demonstrated its ability to carry out the relevant power or duty (DWAF no date). BOCMA had been progressing toward this institutional arrangement, with the Western Cape Regional Office of the department still overseeing management of the WMA (D. Weston, personal communication). With the recent establishment of the BGCMA, however, it is likely that this progression will have slowed considerably while DWS's efforts focus on getting the new CMA up and running.

In addition to having autonomous RBO and agency RBO characteristics, the coordination-focused functions of a CMA tie in with the description of coordinating RBOs. A CMA also has some partnership characteristics in that it can be established on 
the initiative of the community and stakeholders concerned and is therefore also accountable to them. Similarly, a CMA board can be seen as a partnership between various water user groups (DWAF no date), as is evident in BOCMA's CMS (BOCMA 2011).

\section{POLITICS}

When CMAs were first introduced into the discussions around the National Water Act there were both propagators and resisters. A key driving force behind the process was the then Minister of Water Affairs and Forestry, Kadar Asmal, who was very strongly in favor of what can in essence be seen as adaptive comanagement, namely the decentralization of certain water resources management responsibilities to the lowest possible level, and the promotion of high levels of public participation. In addition, concepts such as IWRM and sustainability were a key influence on the National Water Act and related CMA development process.

At the same time, however, there were resisters to this process. These were individuals in DWAF who were resistant to change in general and to the idea of CMAs in particular. Suddenly, these technocrats were faced with new and, at the time, revolutionary ideas (for example, IWRM), which were very different from the department's familiar, day-to-day technical operations. There were also resisters outside DWAF, especially systems modelers, who until then had benefited from the use of their models as part of the department's centralized system of water resources management. These modelers resisted demands for the integration of existing models to support the new decentralized system of water resources management. Instead, the modelers competed against each other, each promoting their own model for use by future CMAs (M. Dent, University of Kwa-Zulu Natal, personal communication, 3 September 2012). These propagator and resister dynamics are in line with the argument that reform processes are likely to be contested by certain actors while others try hard to push them through (Kemerink et al. 2011).

The BOCMA establishment process ran relatively smoothly; intensive stakeholder engagement took place in the Overberg area and Breede River basin, and the National Water Act's guidelines on how the CMA process should be constituted were adhered to closely. The complexities of this process are difficult to establish and may have found expression in the deliberations of the BOCMA Reference Group. Although one would like to assume that the CMA establishment process was conducted in a fully democratic environment (where every stakeholder's voice was heard and everyone's interest was taken into consideration), it is likely that different groups had different levels of power at various points in time. To the untrained eye, stakeholder engagement might look like a dynamically and democratically inclusive process, but in fact, it can still be quite command-and-control driven and dominated by certain powerful actors at the expense of more marginalized actors. How this plays out in the new BGCMA and the Breede-Gouritz WMA in future is an area that needs to be researched further.

The latest 9 WMAs are, like their 19 predecessors, designed to take into consideration river catchment and aquifer boundaries, the future financial viability of the CMA (based on the WMAs' economic realities), stakeholder participation, and equity. What differs from the original process of identifying WMAs is that the
DWS has had to reconsider the CMA management model as a whole, thereby practicing adaptive comanagement's institutional prescription of experimentation. As a result, the DWS has focused particularly on the availability and allocation of funding, capacity, skills, and expertise in WMAs. The rationale behind reducing the number of WMAs has been to combine weaker WMAs with those that have the capacity to manage water resources optimally, from the DWS's point of view.

In addition, the DWS argues that combining CMAs will result in improved distribution of scarce technical skills between institutions, stronger revenue streams, shorter CMA establishment processes, and more direct cooperation and coordination at regional, provincial, and international levels (DWA 2012). In other words, geographical considerations and pragmatism have influenced the department's thinking based on the very limited success of the CMA process to date (D. Weston, personal communication). This new development indicates a move away from ideological considerations to more pragmatic considerations in an attempt to address some of the many problems that have been hampering the CMA development process.

\section{PERFORMANCE}

In the case of BOCMA, it is important to note that although this CMA became operational in 2007, its draft CMS was only released in February 2011 (Page 2012) and had not been signed into effect by the Minister by 2014. Also, as a result of the latest developments, this CMS is no longer valid, and a new one will have to be developed for the BGCMA. It is therefore not possible to make definite statements about how democratic the BGCMA is. We can at most reflect on what BOCMA has achieved to date. These observations link closely to the institutional design of the organization discussed earlier.

Until now, BOCMA's governing board seems to have been doing well in terms of operational decision making, but has not yet had any challenging decisions to make because DWS has not yet delegated many functions to it (D. Weston, personal communication). As stated earlier, the board has a good mix of different representatives and skills.

The vision of BOCMA, as also represented in its CMS, has been in line with the democratic ethos of the South African Constitution and has focused on how it could make a positive and meaningful change to the broader social context within which it is situated. Some of the main components of this vision are inclusion, stakeholder engagement and participation, decentralized decision making, and mediation between human and environmental priorities in an effort to ensure the availability of good-quality water and to assist in poverty alleviation. This translates into the need to support social redress and economic development while also maintaining the functioning of the vitally important aquatic ecosystems in the Breede-Overberg area. In addition, there is a particular focus on the South African context, which centers on addressing water resources reform (aimed at redressing historical inequalities in water access and use; BOCMA 2011, Page 2012).

In terms of stakeholder engagement, the CMS states that stakeholders need to be engaged in an appropriate manner and that "overengagement" should be avoided because it could lead to stakeholder fatigue and a less robust process of engagement 
(BOCMA 2011). This point is based on scientific research that warns that there is not yet a comprehensive and functional approach to public engagement in South Africa (Pollard and Du Toit, unpublished manuscript: http://projects.nri.org/waterlaw/ AWLworkshop/POLLARD-S.pdf). Implicitly contained within BOCMA's purpose are empathy (through the involvement of stakeholders), prior knowledge engagement (through consultation), and patience (when dealing with diverging views from various stakeholders; BOCMA 2011). The process of producing BOCMA's CMS necessitated considerable consultation with a broad and diverse range of stakeholders, in line with BOCMA's vision of playing a central role in the coordination of water resource matters in national, provincial, and local government and in consultation with a variety of partners and stakeholders (Page 2012).

Despite the extensive and overall successful efforts to include as many stakeholders as possible in the CMA establishment and CMS processes, stakeholder engagement has nonetheless reportedly been slow and somewhat irregular (Page 2012). This is likely to have been due to the challenges inherent in involving hundreds of stakeholders.

Another key element of BOCMA's CMS is strategic adaptive management, a South African variant of adaptive management, which has two phases. The first phase is adaptive planning: the establishment of a learning vision in a participative manner and the development of a common understanding of the CMA context as well as operating principles for a number of learning ideals. These ideals include a common future focus, social knowledge sharing, empathy, learning by doing, prior knowledge engagement, patience, experimentation, positive persistence, transdisciplinarity, adaptability, and synergism. The adaptive decision-making phase should involve the development of a detailed management plan that realizes the specific learning objectives and needs to be monitored regularly at various levels and through structured reflection (Roux et al. 2009). Strategic adaptive management is a key component of BOCMA's CMS and lays the foundation for a cooperative environment to promote sustainable development in the WMA (BOCMA 2011).

In addition, a set of values such as integrity, respect, reliability, and accountability has been supposed to underpin the decisions and actions of BOCMA's board members and employees (BOCMA: http://www.bocma.co.za). Accountability is possibly the most important of these values, particularly given the CMA's focus on stakeholder participation. In this regard, BOCMA has been accountable to both its stakeholders and the Minister, although the accountability link to the Minister seems to have been developed better than that to the stakeholders. The board has been giving regular reports to the Minister, but the forums it should have been using to report to the water users in the WMA have not yet been very active or effective. On a positive note, however, the chief executive officer of BOCMA has been going on regular meet-and-greet outings in the catchment to liaise with emerging farmers in the CMA, who probably do not have the same skills, knowledge, resources, and experience as many commercial farmers do (Buthelezi, chief executive officer of BOCMA, personal communication, 28 September 2012).

As a final reflection on democratic functioning, there appears to be a mix of elite and consensus decision making: the Minister of
Water and Sanitation is instrumental in establishing the CMA and appointing its governing board, yet board decisions are made in terms of consensus decision making. As stated previously, such a decision-making mix is essential in the South African context given that in any given catchment, stakeholders are very unevenly capacitated. At the same time, however, it is crucial that the board has an even spread of skills and capacity so that it can carry out its functions effectively and manage the catchment in a way that is beneficial to all stakeholders.

\section{CONCLUSION}

It is clear that the establishment process of CMAs, in South Africa generally, and BOCMA in particular, can be linked effectively to the institutional prescriptions that form part of adaptive comanagement, namely collaboration, experimentation, and a bioregional approach. Furthermore, this topic has lent itself to an interesting analysis when applying the component of the framework that focuses on different possible rule types, types of RBOs, as well as the political and performance dimensions of $\mathrm{RBO}$ formation. We next briefly reflect on each of these aspects in the context of the future operations of the BGCMA in particular, and CMAs more generally. We subsequently turn our attention to some interesting and controversial questions that are being asked about the continued existence of CMAs in South Africa, and finally, we briefly reflect on some lessons that the South African process of CMA establishment might yield for other countries.

In terms of authority rules, CMAs will most likely continue to have governing boards, which are representative of all stakeholders and their interests in the WMA and are able to exercise democratic control. In line with the developments around BOCMA and the BGCMA that has now been established, a new governing board with new stakeholders will of course need to be appointed, which may complicate the existing situation and processes in the newly established CMA. The Minister of Water and Sanitation is likely to continue to have a key role in CMA establishment, and given recent developments around the reform of CMAs, the DWS may have an even bigger role to play regarding the establishment and running of CMAs in future. A case in point is the recognition that a governing board of a CMA needs to have the skills and capacity to function effectively and that stronger intervention by the DWS may be required to achieve this. The learning that has informed this realization links to the institutional prescription of experimentation that forms part of adaptive comanagement and the idea of effectively adapting to challenges as and when they emerge. Whether the board that will eventually be appointed for the BGCMA will be able to address the challenges presented to it remains to be seen, and more research into the matter will be required in future.

Looking at the aggregation rule type as well as the performance of the CMA, the need for the application of aggregation rules (where individual views are accommodated in the stakeholder consultation phase) may present several problems to DWS's attempts to get the BGCMA up and running. Given that an extensive stakeholder consultation process was already followed when setting up BOCMA, it may prove very difficult to run a process of a similar magnitude to inform the operationalization of the new BGCMA. This is both because of time constraints as well as probable high levels of stakeholder fatigue in the Breede- 
Gouritz WMA. A similar problem will be encountered in other CMAs, e.g., Inkomati, that have also already had broad stakeholder consultations. Stakeholder fatigue in the case of CMA establishment is the result of stakeholders being asked to invest in similar processes over and over again without seeing any worthwhile results. When they are no longer willing to participate, the ability to adapt and experiment is rendered increasingly difficult, and the chances of success drop considerably.

The potential problems associated with stakeholder consultation in the future BGCMA and other CMAs that are discussed here are closely linked to adaptive comanagement's institutional prescription of experimentation. As part of its adapted response to CMA establishment, there are indications that future CMA establishment processes such as that of the BGCMA will be conducted by means of more streamlined methods that focus primarily on efficiency and only draw in stakeholders where needed (D. Weston, personal communication). Although this development may speed up the CMA establishment process countrywide, it may also have negative consequences for more marginalized stakeholders to participate in the CMA process and to ensure that their interests are represented. These negative consequences, in turn, may have a damaging effect on the legitimacy of decisions made and whether the implementation of these decisions turns out to be successful. Although experimentation is necessary, it should only be applied in conjunction with measured forward thinking and planning. On a more positive note, a continued focus on egalitarian decision making through democratic agreement where all board members' views are taken into consideration will stand the new BGCMA in good stead. In terms of bioregionalism and boundary rules, DWS's decision to consolidate existing WMAs, combining weaker ones with better resourced ones to maximize their functioning and performance, demonstrates that these are not static concepts and that boundaries can be redefined if and when the need arises. From a political perspective, the changes to the WMA structure seem to have been the result of geographical and pragmatic considerations, given the very limited success of the CMA process to date, and seem to have replaced the ideological considerations that drove the process of conceptualizing the idea of CMA establishment in the 1990s. It now remains to be seen whether these pragmatic changes will have the desired effect and will enable DWS to increase considerably the success of the CMA establishment process. Regarding CMA performance, the amalgamation of weaker and stronger CMAs will hopefully also enable the BGCMA to function according to the concept of strategic adaptive management, which has underpinned the CMS of its predecessor, and to thereby realize both a cooperative environment and sustainable development in the WMA.

In terms of information rules, scientific and technocratic knowledge seem to have been a key influence on BOCMA's CMS, the document containing important knowledge about the strategy and functioning of the CMA. Although this contribution has been very valuable, other kinds of knowledge should also be included in the development of the new CMS for the BGCMA to enable it to deal with the complexities characterizing the Breede-Gouritz WMA.

Looking at pay-off rules, while BOCMA received start-up funding from various sources, the BGCMA will need to become financially independent to implement the CMA that it will be developing. Also, related to pay-off rules, the question of "who benefits and for what" (Strange 1996) cannot yet be answered in the case of the BGCMA. At this stage, an assumption can be made that strong and well-resourced actors (for example, government, scientists, consultants, agriculture, and tourism) are likely to receive most of the benefits. This indicates that the National Water Act has not yet achieved its objectives of socioeconomic development and redress because those who continue to benefit from its implementation are already powerful actors, while poor and marginalized actors continue to be disadvantaged.

In terms of RBO types, the move from 19 to 9 larger, consolidated CMAs suggests that CMAs in South Africa may, at least in the short to medium term, be moving further away from autonomy status and increasingly toward agency status. The National Water Resources Strategy 2 (DWA 2013) states that DWS will assist CMAs in building capacity to manage a range of functions that ultimately are to be delegated to them. These functions include, among others, water use authorization, water resources protection, water quality management, and water resources planning. The DWS will also be considerably more involved in CMA establishment, with "a dedicated high-level team" to drive the establishment and operationalization of the nine CMAs by 2016. This high-level team will also communicate to affected water sector institutions and other stakeholders regarding CMA establishment and the devolution of powers and functions (DWA 2013). In addition, our research suggests that private consultants will continue to play an important part in assisting DWS and CMAs with the CMA establishment process and the drafting of CMSs. The DWS's increased involvement in CMA establishment and functioning may be because it is trying to take back control over the process of CMA establishment, which has been lagging considerably.

Having reflected on the possible way forward for the BGCMA and other CMAs in the context of the theoretical framework that has been applied here, we now reflect on some rather interesting and controversial questions that we encountered when doing this research. These questions deal with the issue of whether CMAs in South Africa, given the numerous challenges that have characterized attempts to establish them, should be allowed to have a future at all. A. Anderson, in a personal communication to us, stated that while it makes sense to define WMAs according to hydrological boundaries and involve as many stakeholders as possible within a WMA, it has nonetheless been very difficult to establish CMAs in South Africa, especially when considering the lag time between stakeholder engagement and final establishment. Other issues that have made CMA establishment difficult, especially in the case of the Inkomati CMA, have been a waterstressed situation; diversity in stakeholders' resources, knowledge, experience, and skills; and extreme socioeconomic disparities (Brown 2011). With the considerable water governance challenges facing South Africa, and the DWS struggling to get many of the fundamentals in place (for example, water use licences), it might be relevant to question whether all of the resources that have been spent and are still being spent on the CMA process have made this process worthwhile. This question is particularly pertinent given the many inherent challenges the country faces (such as the inequalities among stakeholders in a WMA), which play out in efforts to establish CMAs and can render the process very complex. 
Brown (2011) writes about her research focusing on the establishment of the Inkomati CMA and the transformation of existing irrigation boards into water user associations in the Inkomati WMA. She concludes that there may be substantial weaknesses in the participatory governance model, and that such approaches, if not sufficiently controlled by government interventions, may in fact reinforce inequitable outcomes. Based on her findings, Brown (2011) argues that something of a "cultural revolution" of how different stakeholder groupings in South Africa perceive each other's needs is required before a level of comprehensive and effective stakeholder participation can take place. However, the development of such a revolution may take many years, and given the very slow progress in CMA establishment to date, Brown (2011:183) poses a controversial question: "If the end goal of water reforms was redress, would it have been a more effective solution for a government with such an overwhelming majority to have pursued a direct state-led redress agenda whilst supporting empowerment programmes to expedite the cultural revolution, rather than participatory governance?"

Finally, we attempt to answer the important question of whether the South African case of CMA establishment can yield lessons for other countries that are attempting to establish IWRM institutions. As we have shown, South Africa certainly provides very interesting and unique examples of CMA establishment. These are marked predominantly by the challenge of bringing together different stakeholders given the country's unique community structures as well as the considerable disparities in power, agency, and resources that characterize the stakeholder landscape in the different WMAs. Although each country will have its own challenges, taking some key learning points from the South African context may be useful, especially given the extremity and magnitude of the challenges that the DWS has faced in its attempts to facilitate the establishment of CMAs. Given our analysis, perhaps the single most important lesson would be the need to determine how the level of enthusiasm and interest in stakeholder engagement processes can remain high, particularly if stakeholders have been asked to participate repeatedly in similar processes. The success of IWRM institutions such as CMAs is likely to depend considerably on the sustainability of its stakeholder engagement processes as well as its ability to assimilate and use successfully the information and inputs that it has gathered from such endeavors.

Responses to this article can be read online at: http://www.ecologyandsociety.org/issues/responses. $\mathrm{php} / 8417$

\section{Acknowledgments:}

We acknowledge the editors of this special feature for providing us the opportunity to collaborate with them on this research on better understanding river basin organizations. We also acknowledge all interview respondents for the valuable insights they contributed to our research. An earlier version of this article was published as: Meissner, R., and N. Funke. 2014. The politics of establishing catchment management agencies in South Africa: the case of the
Breede-Overberg Catchment Management Agency. Pages 184-209 in D. Huitema and S. Meijerink, editors. The politics of river basin organisations, coalitions, institutional design choices and consequences. Edward Elgar, Cheltenham, UK. The authors thank Edward Elgar Publishing for kindly giving permission for the use of this material.

\section{LITERATURE CITED}

Armitage, D. R., R. Plummer, F. Berkes, R. I. Arthur, A. T. Charles, I. J. Davidson-Hunt, A. P. Diduck, N. C. Doubleday, D. S. Johnson, M. Marschke, P. McConney, E. W. Pinkerton, and E. K. Wollenberg. 2009. Adaptive co-management for socialecological complexity. Frontiers in Ecology and the Environment 7(2):95-102. http://dx.doi.org/10.1890/070089

Breede-Overberg Catchment Management Agency (BOCMA). 2009. Stakeholder engagement process. Newsletter 1, November 2009. Breede-Overberg Catchment Management Agency, Worcester, South Africa.

Breede-Overberg Catchment Management Agency (BOCMA). 2010. A vision determined by all. Newsletter 3, July 2010. BreedeOverberg Catchment Management Agency, Worcester, South Africa.

Breede-Overberg Catchment Management Agency (BOCMA). 2011. Draft Breede-Overberg Catchment Management Strategy. Breede-Overberg Catchment Management Agency, Worcester, South Africa.

Brown, J. 2011. Assuming too much? Participatory water resource governance in South Africa. Geographical Journal 177 (2):171-185. http://dx.doi.org/10.1111/j.1475-4959.2010.00378.x

Claassen, M. 2013. Integrated water resource management in South Africa. International Journal of Water Governance 1 (3-4):323-338. http://dx.doi.org/10.7564/13-ijwg12

Denison, J., and S. Manona. 2007. Principles, approaches and guidelines for the participatory revitalisation of smallholder irrigation schemes (volume 1 of 2): a rough guide for irrigation development practitioners. WRC report TT 308/07. Water Research Commission, Pretoria, South Africa. [online] URL: http://www.wrc.org.za/Knowledge Hub Documents/Research Reports/TT 308-09 REVISED Agricultural Water management. pdf

Department of Water Affairs (DWA). 2012. Business case for the Breede-Gouritz Catchment Management Agency. Department of Water Affairs, Pretoria, South Africa. [online] URL: https://www. dwa.gov.za/io/Docs/CMA/Businesss $\% 20$ Case/Business $\% 20$ Case $\%$ 20for $\% 20$ Breede $\% 20$ Gouritz $\% 20$ CMA.pdf

Department of Water Affairs (DWA). 2013. National water resources strategy: water for an equitable and sustainable future. Second edition. Department of Water Affairs, Pretoria, South Africa. [online] URL: https://www.dwa.gov.za/nwrs/LinkClick. aspx?fileticket $=$ CIwWyptzLRk $\% 3$ D\&tabid $=91 \&$ mid $=496$

Department of Water Affairs and Forestry (DWAF). No date. Water management institutions overview. Department of Water Affairs and Forestry, Pretoria, South Africa. [online] URL: https://www.dwa.gov.za/documents/publications/WMIoverview.pdf 
Department of Water Affairs and Forestry (DWAF). 2004a. A history of the first decade of water services delivery in South Africa 1994-2004: meeting the millennium development goals. Department of Water Affairs and Forestry, Pretoria, South Africa. [online] URL: https://www.dwa.gov.za/documents/ publications/firstdecade.pdf

Department of Water Affairs and Forestry (DWAF). $2004 b$. Breede Water Management Area: internal strategic perspective. Version 1. Report PWMA 18/000/00/0304. Department of Water Affairs and Forestry, Pretoria, South Africa.

Department of Water Affairs and Forestry (DWAF). 2004c. Breede Water Management Area: proposal for the establishment of a catchment management agency. Department of Water Affairs and Forestry, Pretoria, South Africa.

Department of Water Affairs and Forestry (DWAF). 2004d. National water resources strategy. First edition. Department of Water Affairs and Forestry, Pretoria, South Africa. [online] URL: https://www.dwa.gov.za/Documents/Policies/NWRS/Default.htm

Du Toit, D., and S. Pollard. 2008. Updating public participation in IWRM: a proposal for a focused and structured engagement with catchment management strategies. Water $S A$ 34(6):707-713. [online] URL: http://www.scielo.org.za/scielo.php?script= sci abstract\&pid=S1816-79502008000600007\&lng=en\&nrm=iso\&tlng= $\underline{\text { en }}$

Funke, N., K. Nortje, K. Findlater, M. Burns, A. Turton, A. Weaver, and H. Hattingh. 2007. Redressing inequality: South Africa's new water policy. Environment 49(3):10-23. http://dx.doi. org/10.3200/envt.49.3.10-25

Huitema, D., and S. Meijerink, editors. 2016. The politics, design, and effects of a bioregional approach: the case of river basin organizations. Ecology and Society SF116. [online] URL: http:// www.ecologyandsociety.org/issues/view.php?sf=116

Huitema, D., E. Mostert, W. Egas, S. Moellenkamp, C. PahlWostl, and R. Yalcin. 2009. Adaptive water governance: assessing the institutional prescriptions of adaptive (co-)management from a governance perspective and defining a research agenda. Ecology and Society 14(1):26. [online] URL: http://www.ecologyandsociety. org/vol14/iss1/art26/

Jonker, L. 2007. Integrated water resources management: the theory-praxis-nexus, a South African perspective. Physics and Chemistry of the Earth 32(15-18):1257-1263. http://dx.doi. org/10.1016/j.pce.2007.07.031

Kemerink, J. S., R. Ahlers, and P. van der Zaag. 2011. Contested water rights in post-apartheid South Africa: the struggle for water at catchment level. Water SA 37(4):585-594. http://dx.doi. org/10.4314/wsa.v37i4.16

Lee, K. N. 1993. Compass and gyroscope: integrating science and politics for the environment. Island Press, Washington, D.C., USA.

Lee, K. N. 1999. Appraising adaptive management. Conservation Ecology 3(2):3. [online] URL: http://www.ecologyandsociety.org/ vol3/iss $2 / \operatorname{art} 3 /$
McConkey, G. E., W. D. Enright, J. A. Roberts, and R. Khan. 2005. The development of a catchment management agency for the Breede River, Western Cape, South Africa. Department of Water Affairs and Forestry, Cape Town, South Africa.

Meissner, R., N. Funke, S. Nienaber, and C. Ntombela. 2013. The status quo of research on South Africa's water resource management institutions. Water $S A$ 39(5):721-732. http://dx.doi. org/10.4314/wsa.v39i5.17

Olsson, P., C. Folke, and T. Hahn. 2004. Social-ecological transformation for ecosystem management: the development of adaptive co-management for a wetland landscape in southern Sweden. Ecology and Society 9(4):2. [online] URL: http://www. ecologyandsociety.org/vol9/iss4/art2

Page, R. R. 2012. Description of three environmental comanagement systems in the Western Cape. Thesis. University of Stellenbosch, Stellenbosch, South Africa. [online] URL: http:// hdl.handle.net/10019.1/20140

Pegram, G., G. Mazibuko, B. Hollingworth, and E. Anderson. 2006. Strategic review of current and emerging governance systems related to water in the environment in South Africa. Report 1514/1/06. Water Research Commission, Pretoria, South Africa. [online] URL: http://www.wrc.org.za/Pages/DisplayItem.aspx? ItemID $=3556 \&$ FromURL $=\% 2 \mathrm{FPages} \% 2 \mathrm{FAllKH} \cdot \mathrm{aspx} \% 3 \mathrm{~F}$

Plummer, R., and D. Armitage. 2007. A resilience-based framework for evaluating adaptive co-management: linking ecology, economics and society in a complex world. Ecological Economics 61(1):62-74. http://dx.doi.org/10.1016/j.ecolecon.2006.09.025

Republic of South Africa. 1996. Constitution of the Republic of South Africa (No. 108). Government Printer, Pretoria, South Africa. [online] URL: http://www.gov.za/sites/www.gov.za/files/ images/a108-96.pdf

Republic of South Africa. 1998. National Water Act (No. 36). Government Gazette 26 August 1998. Government Printer, Pretoria, South Africa. [online] URL: http://www.energy.gov.za/ files/policies/act nationalwater36of1998.pdf

Republic of South Africa. 2014. Establishment of the BreedeGouritz Catchment Management Agency through extending the boundary and area of operation of the Breede-Overberg Catchment Management Agency in terms of section 78(4) of the National Water Act, 1998 (Act No. 36 of 1998). Government Gazette 23 May 2014. Government Printer, Cape Town, South Africa. [online] URL: http://www.gov.za/sites/www.gov.za/ files/37677 gon412.pdf

Roux, D. J., K. Murray, and E. van Wyk. 2009. Enabling effective learning in catchment management agencies: a philosophy and strategy. Report TT 421/09. Water Research Commission, Pretoria, South Africa. [online] URL: http://www.wrc.org.za/ Pages/DisplayItem.aspx?ItemID $=8938 \&$ FromURL $=\% 2$ FPages $\%$ 2FDefault.aspx $\% 3 \mathrm{~F}$

Schreiner, B., B. van Koppen, and T. Khumbane. 2002. From bucket to basin: a new paradigm for water management, poverty eradication and gender equity. Pages 127-140 in A. Turton and R. Henwood, editors. Hydropolitics in the developing world: a 
southern African perspective. African Water Issues Research Unit, Pretoria, South Africa.

Strange, S. 1996. The retreat of the state: the diffusion of power in the world economy. Cambridge University Press, Cambridge, UK. http://dx.doi.org/10.1017/cbo9780511559143

Van Averbeke, W. 2008. Best management practices for small-scale subsistence farming on selected irrigation schemes and surrounding areas through participatory adaptive research in Limpopo Province. Report TT344/08. Water Research Commission, Pretoria, South Africa. [online] URL: http://www.wrc.org.za/Knowledge $\%$ 20Hub\%20Documents/Research $\% 20$ Reports/TT $\% 20344$-webAgricultural $\% 20$ water $\% 20$ management.pdf 